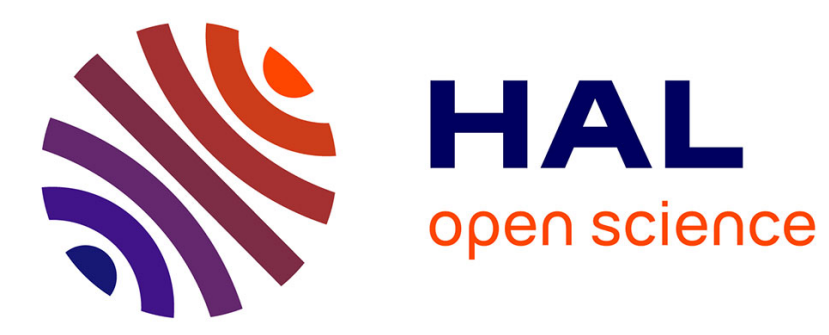

\title{
Measuring stress intensity factors with a camera: Integrated digital image correlation (I-DIC)
}

\author{
François Hild, Stéphane Roux
}

\section{To cite this version:}

François Hild, Stéphane Roux. Measuring stress intensity factors with a camera: Integrated digital image correlation (I-DIC). Comptes Rendus Mécanique, 2006, 334, pp.8-12. 10.1016/j.crme.2005.11.002 . hal-00322201

\section{HAL Id: hal-00322201 \\ https://hal.science/hal-00322201}

Submitted on 17 Sep 2008

HAL is a multi-disciplinary open access archive for the deposit and dissemination of scientific research documents, whether they are published or not. The documents may come from teaching and research institutions in France or abroad, or from public or private research centers.
L'archive ouverte pluridisciplinaire HAL, est destinée au dépôt et à la diffusion de documents scientifiques de niveau recherche, publiés ou non, émanant des établissements d'enseignement et de recherche français ou étrangers, des laboratoires publics ou privés. 


\title{
Measuring stress intensity factors with a camera: Integrated digital image correlation (I-DIC)
}

\section{Mesure de facteurs d'intensité des contraintes avec une caméra : corrélation d'images numériques intégrée (CINI)}

\author{
François Hild, ${ }^{\mathrm{a}}$ Stéphane Roux ${ }^{\mathrm{b}}$ \\ ${ }^{a}$ LMT-Cachan, ENS de Cachan / CNRS UMR 8535 / Université Paris 6, 61 Avenue du Président Wilson \\ F-94235 Cachan Cedex, France \\ ${ }^{\mathrm{b}}$ Laboratoire Surface du Verre et Interfaces, Unité Mixte de Recherche CNRS/Saint-Gobain, 39 Quai Lucien Lefranc \\ F-93303 Aubervilliers Cedex, France
}

\begin{abstract}
A novel "integrated" approach coupling image correlation and elastic displacement field identification provides a powerful and accurate tool to evaluate mode I and II stress intensity factors. This technique is applied to silicon carbide subjected to a sandwiched three-point bend test, using digital pictures obtained in optical microscopy where the pixel physical scale is about $2 \mu \mathrm{m}$. A crack whose maximum opening is $500 \mathrm{~nm}$ can be detected and its geometry identified. The toughness is determined well within a $10 \%$ uncertainty.

\section{Résumé}

Une nouvelle technique de corrélation d'images, dite "intégrée", est proposée. Couplée à l'identification d'un champ de déplacement d'un milieu élastique, elle permet de déterminer les facteurs d'intensité des contraintes en modes I et II. Cette technique est appliquée à un carbure de silicium lors d'un essai de préfissuration, en exploitant des images de microscopie optique dont la taille physique du pixel vaut $2 \mu \mathrm{m}$. Une fissure dont l'ouverture maximale est d'ordre $500 \mathrm{~nm}$ est identifiée et sa géométrie estimée. Les facteurs d'intensité des contraintes sont déterminés avec une incertitude bien inférieure à $10 \%$.
\end{abstract}

Key words: Rupture ; photomechanics ; brittle material ; toughness

Mots-clés : Rupture; photomécanique; matériau fragile; ténacité 


\section{Version française abrégée}

Dans cette Note, il est proposé de développer une approche intégrée de la mesure de champs cinématiques et d'identification de paramètres de fissuration par corrélation d'images. Contrairement à l'analyse séquentielle de la mesure puis de l'identification, en particulier pour l'étude des fissures [3,4,5], on décompose a priori le champ de déplacement recherché sur une base fonctionnelle $\mathbf{U}_{i}$ correspondant à des solutions de problèmes élastiques. Il s'agit alors de minimiser la fonctionnelle (1) par rapport aux amplitudes inconnues $a_{i}$. Dans le cadre proposé, ceci revient à résoudre un système linéaire (2). Cette démarche est appliquée à un essai de préfissuration [7]. Le montage expérimental est schématisé sur la figure 1a. Il a été utilisé sur un carbure de silicium. Il permet de générer une fissure stable à partir d'une entaille. Les figures $1 b, c$ montrent les images acquises avant et après préfissuration. Celles-ci ont été obtenues à l'aide d'un microscope à longue distance frontale couplé à une caméra CCD 8 bits. Aucune fissure ne peut être vue par simple inspection des images.

La figure 2 montre les deux composantes (perpendiculaire et parallèle à la direction de fissuration) du champ de déplacement mesuré lorsqu'il est décomposé sur 8 champs (trois composantes de mouvement de corps rigide, une composante de déformation uniforme dans la direction de fissuration, deux composantes singulières de modes I et II et deux composantes subsingulières de modes I et II). La carte d'erreur locale d'identification au sens de l'équation (1) est également donnée. Sur celle-ci on observe très nettement la fissure. Sur le bord supérieur droit on observe également un résidu significatif qui peut être lié à la présence d'une porosité sub-surfacique. Hormis ces deux résidus, le champ d'erreur est très homogène, et à un un niveau très faible permettant ainsi de valider le choix de la base fonctionnelle.

Sur la figure 3 sont données les valeurs des facteurs d'intensité des contraintes en fonction de la position $\mathbf{x}_{0}$ de la fissure. Pour chaque position, l'erreur globale $\mathcal{T}\left(\mathbf{x}_{0}\right)$ est évaluée et sa minimisation permet de déterminer la position de la fissure la plus probable. Elle est déterminée avec une incertitude de l'ordre de $\pm 2 \mu \mathrm{m}$ perpendiculairement à la direction de la fissure, et de $\pm 10 \mu \mathrm{m}$ le long de son extension. On obtient alors des valeurs de $K_{I}=2.30 \pm 0.15 \mathrm{MPa} \sqrt{\mathrm{m}}$ et $K_{I I}=0.05 \pm 0.05 \mathrm{MPa} \sqrt{\mathrm{m}}$. Les valeurs courantes de ténacité $K_{c}$ varient entre 2.7 et $3 \mathrm{MPa} \sqrt{\mathrm{m}}$, supérieures aux valeurs trouvées ici. Bien que la fissure ne se propage pas parallèlement à la direction de chargement, on montre que le mode I est très largement dominant. On notera enfin que l'amplitude maximale des discontinuités de déplacement perpendiculairement à la direction de fissure sont de $500 \mathrm{~nm}$ et parallèlement de l'ordre de $30 \mathrm{~nm}$.

Many design procedures need to evaluate precisely the toughness of materials, and above all ceramics and glasses, which essentially suffer from their brittleness. Ideally, in situ experimental measurements would be extremely valuable to assess correctly the remaining lifetime of a structure in service or to determine the ultimate load leading to failure for brittle materials. This however requires accurate measurements of strains or displacements that are difficult to obtain for brittle materials. Classical approaches to the measurement of toughness are based on mechanical tests where notches (assumed to be cracks or crack initiators) are created or in indentation experiments [1]. In all cases, the measurement of the crack length and crack opening is a crucial step to get a quantitative estimate of stress intensity factors and toughnesses. Because of their brittleness, ceramics and glass have very small crack openings, and hence the determination of the crack tip location is a major challenge that requires generally a careful instrumentation or preparation of the sample.

The recent advances in digital picture acquisition, in terms of increasing quality, fine resolution, and low cost, and its use through Digital Image Correlation (DIC) [2] is appealing to reach this goal. The latter

Email addresses: hild@lmt.ens-cachan.fr (François Hild,), stephane.roux@saint-gobain.com (Stéphane Roux). 
technique has known very substantial developments recently. It consists in analyzing displacement fields from textured surface images through the estimate of translations that maximize the cross-correlation of zones of interest (i.e., small regions of the images). This technique has been applied successfully to a number of different materials and geometries even containing cracks [3,4]. In particular, crack tip detection in $\mathrm{SiC}$ samples has been the focus of a recent study [5]. A novel approach based on the correlation between numerical images of the sample face at different stages of loading is proposed. Although being based on optical microscopy images whose pixel size is about $2 \mu \mathrm{m}$, the proposed data analysis is able to reveal crack openings that, at most, reach a few hundreds of nanometers, namely a much smaller resolution than one pixel, and even smaller than the light wavelength. More importantly, the crack opening displacement field and hence the crack tip location are obtained altogether with a very good spatial resolution. Mixed loading modes can be detected and quantified. No special sample preparation is required, and apart from the microscope optics, this technique does not require any specific and sophisticated equipment.

\section{Proposed Approach}

The displacement field, $\mathbf{u}(\mathbf{x})$, between two images, described as gray-level functions, $f$ and $g$, is decomposed over a set of test functions, $\mathbf{u}(\mathbf{x})=\sum_{i} a_{i} \mathbf{U}_{i}(\mathbf{x})$, where $\mathbf{U}_{i}$ are chosen at will, and $a_{i}$ are to be determined. By making the hypothesis of a passive advection of the texture, $g(\mathbf{x})=f[\mathbf{x}+\mathbf{u}(\mathbf{x})]$, and a first order Taylor expansion, the displacement is estimated through the minimisation of

$$
\mathcal{T}=\int[g(\mathbf{x})-f(\mathbf{x})-\mathbf{u}(\mathbf{x}) \cdot \nabla f(\mathbf{x})]^{2} \mathrm{~d} \mathbf{x}
$$

The measurement of a displacement field is therefore an ill-posed problem. The displacement can only be measured along the direction of the intensity gradient. Consequently, additional hypotheses have to be proposed to regularize and solve the problem. In the present case, it is given by the decomposition of the displacement field as a linear combination of suitable test functions $\mathbf{U}_{i}$. The different amplitudes $a_{i}$ are then computed from the solution of a linear system of equations

$$
a_{j} \int\left[\mathbf{U}_{i}(\mathbf{x}) \otimes \mathbf{U}_{j}(\mathbf{x})\right]:[\nabla f(\mathbf{x}) \otimes \nabla f(\mathbf{x})] \mathrm{d} \mathbf{x}=\int[f(\mathbf{x})-g(\mathbf{x})] \nabla f(\mathbf{x}) \cdot \mathbf{U}_{i}(\mathbf{x}) \mathrm{d} \mathbf{x}
$$

The difficulty lies in the lack of differentiability of the image texture $f$ so that the above formula does not hold for arbitrary displacement amplitudes. A multi-scale approach has to be devised to first determine the long wavelength modes of the displacement on coarse-grained or low-pass filtered images, and progressively finer and finer details of the original image are restored once a first estimate of the displacement has been determined and taken into account through a first correction. To determine the crack geometry and properties, the chosen basis consists of rigid body motions (translation and rotation, i.e., three degrees of freedom), a displacement field induced by a homogeneous tension along the crack orientation (i.e., the so-called T-stress, corresponding to one degree of freedom), mode I and II plane crack fields (i.e., two degrees of freedom given by the values of the stress intensity factors $K_{I}$ and $K_{I I}$ ), i.e., singular strain fields which correspond to displacement discontinuities either normal (mode I) or parallel to the crack face (mode II). Two additional degrees of freedom are introduced as the sub-singular displacement fields associated to modes I and II. These eight functions allow us to account very accurately for the image differences in the vicinity of the crack tip. For this procedure to be well defined, one has to indicate the crack tip position $\mathbf{x}_{0}$, and crack orientation $\theta$, since they are included in the analytic expression of the five last test functions. For each choice of the crack geometry parameters, the decomposition can be performed and a global quality factor can be obtained by using Eq. (1). This feature can in turn 
be utilized to optimize the crack tip geometry parameters to obtain the best location in the sense of lowest global error. Moreover, a local map of non-resolved differences can be obtained. It may thus reveal systematic errors that may lead to revisit the basis of functions used to analyse the image to account for these unresolved components. Let us mention that a similar strategy exploiting the global quality factor minimisation can also be used to determine elastic properties of the considered solids beyond geometry determination [6]. The setting would be very similar to the present application.

\section{Example: analysis of a sandwiched-beam experiment}

This approach is tested experimentally on a silicon carbide ( $\mathrm{SiC})$ sample. The material examined herein, called SiC-100 and made by Céramiques \& Composites (France), is naturally sintered. The residual porosity is of the order of $1.8 \%$ and the average grain size is equal to $5 \mu \mathrm{m}$. To obtain a stable crack propagation, a sandwiched beam setup [7] with steel facings was subjected to a three-point bend test as schematically shown in Fig. 1a. The ceramic beam sample is sandwiched between two steel beams whose dimensions are: thickness $b_{A}=b_{B}=9 \mathrm{~mm}$ (perpendicular to the figure plane), width $w_{A}=5.5 \mathrm{~mm}$, $w_{B}=7 \mathrm{~mm}$, length $l_{A}=l_{B}=25 \mathrm{~mm}$. For the ceramic beam, $b_{N}=3 \mathrm{~mm}, w_{N}=5 \mathrm{~mm}, l_{N}=25 \mathrm{~mm}$. The initial notch size $a$ is of the order of $0.4 w_{N}$. The outer span of the bend test is $L=20 \mathrm{~mm}$. An initial notch was machined on the tensile loaded face of the $\mathrm{SiC}$ sample, and a load is applied to initiate a crack. Once this sharp crack is obtained, the sample is unloaded and the facings are removed. Let us concentrate in this study on the first stage. The difficulty with the chosen geometry is that the stress state in the vicinity of the crack tip is complex and crucially dependent on the friction of the contact surfaces between the ceramic sample and the steel beams. Therefore it cannot be used for an analytic or numerical identification of the stress intensity factors [5].
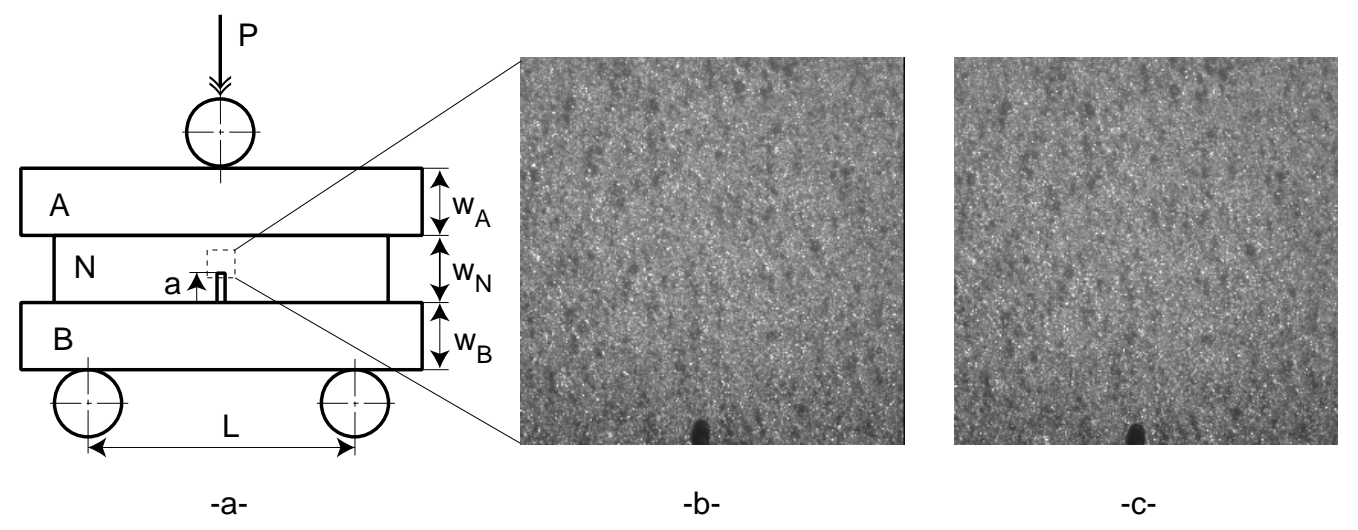

Figure 1. Geometry of the sandwiched beam set-up (a). The brittle sample (N) is put in between two steel beams (A and B). A three-point bend test is performed. A first stable crack can be initiated. Initial (b) and cracked (c) SiC sample face. In the middle of the lower side, the black spot is the mark of the notch, from which a crack propagates.

The free lateral faces can be observed during the test. By using a long distance microscope, pictures of the sample are taken in the initial unloaded stage, and at the crack initiation point. This high quality optics allows one to obtain pictures with an excellent spatial resolution. The physical pixel size was estimated to be $1.85 \mu \mathrm{m}$. Digital pictures are taken with a CCD camera (resolution: $1008 \times 1016$ pixels, 8-bit dynamic range). A long-distance microscope is used to observe one part of the lateral surface of the ceramic sample. The main advantage is that a microscopic resolution can be achieved from a longer 
distance than conventional microscopes. Figures $1 b$,c show the two images. In spite of the high quality of the photographs, it is impossible with bare eyes to see the crack.

This method was first evaluated in terms of performance. For a $512 \times 512$ pixel zone of interest, the average error in translation measurement using the above tool reduced to the first three trial fields is less than $3 \times 10^{-3}$ pixel for artificial displacements ranging from 0 to 1 pixel with 0.1 pixel increments. For the reference picture (Fig. 1b), it corresponds to a physical length of $6 \mathrm{~nm}$. Similarly, the detection of a uniform strain is tested by using a suited set of test functions (rigid body motion and uniform strains), through a numerically generated false view of a strained sample. For strain levels of the order of $10^{-3}$, a relative error was found to be less than $2 \%$ for all tested cases. For $5 \times 10^{-4}$ and $2.5 \times 10^{-4}$ strains, an error of $3 \%$ and $10 \%$ was observed, respectively.

In the present case, the multi-resolution scheme was used to determine the mean global translation, but once the latter was corrected for, the remaining displacement amplitude was small enough not to require such a scheme. By using the complete eight dimensional approach, the amplitude of each test function is estimated, and using known values of the elastic properties of silicon carbide (Young's modulus $E=$ $410 \mathrm{GPa}$, and Poisson's ratio $\nu=0.15)$, the crack opening displacements can be translated into stress intensity factors. Figure 2 shows the measured displacement fields (components normal and parallel to the crack face) for a given crack position. The identification error map is also shown on the same figure. On the latter, the crack appears clearly as a straight slit. On the upper right corner, a significant residual presumably reflects the presence of a sub-superficial pore (which cannot be seen on the direct images). Apart from the crack and such isolated defects, one can observe on this map that no significant increase in error can be detected either at the crack tip, or remote from it, indicating that the assumed functional basis for the displacement field is well suited to the case at hand.
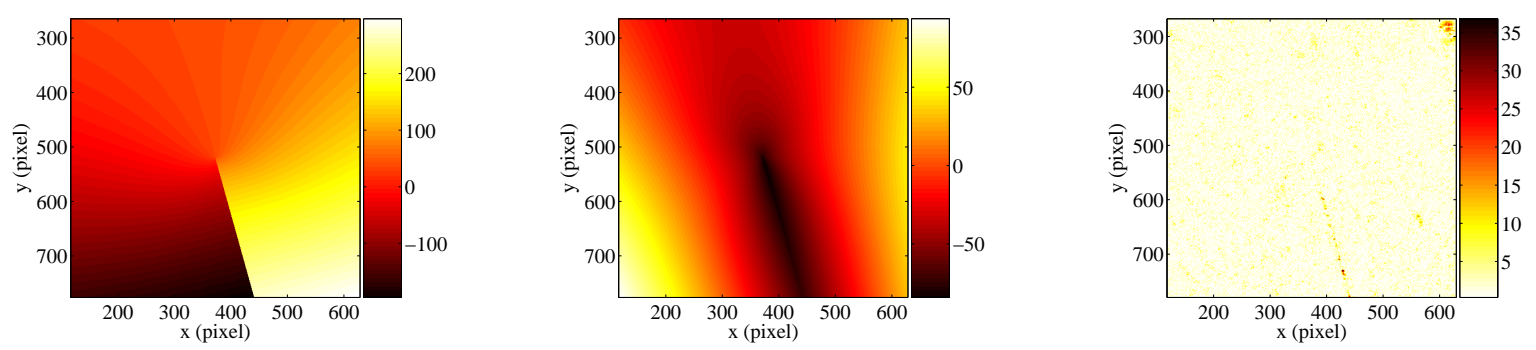

Figure 2. Maps of normal (mode I) (a) and tangential (mode II) (b) displacements in nanometers and local residual error (c) in gray levels.

Figure 3 shows the three fields of mode I and II stress intensity factors and relative global quality as functions of the crack tip co-ordinates. At each trial crack tip position $\mathbf{x}_{0}$, the global residual $\mathcal{T}\left(\mathbf{x}_{0}\right)$ [Eq. (1)] is computed for the optimum displacement field. The relative global quality, $Q\left(\mathbf{x}_{0}\right)$, shown in Fig. 3c is defined as $Q\left(\mathbf{x}_{0}\right)=\left(\mathcal{T}\left(\mathbf{x}_{0}\right)-\mathcal{T}^{*}\right) / \mathcal{T}^{*}$, where $\mathcal{T}^{*}$ is the absolute minimum of the global residual.

Minimization of the error allows one to locate the crack tip with an uncertainty of about $\pm 2 \mu \mathrm{m}$ perpendicular to its mean orientation and about $\pm 10 \mu \mathrm{m}$ along its extension. This provides an estimate for $K_{I}=2.30 \pm 0.15 \mathrm{MPa} \sqrt{\mathrm{m}}$ and $K_{I I}=0.05 \pm 0.05 \mathrm{MPa} \sqrt{\mathrm{m}}$. Generally accepted values for the toughness $K_{c}$ lie in the range from 2.7 to $3 \mathrm{MPa} \sqrt{\mathrm{m}}$, somewhat larger than the present determination. Ceramic materials are expected to fail essentially in mode I (normal crack opening). In the present case, the fracture propagated at an angle with respect to the symmetry axis, and thus one may have expected a mixed fracture mode. The result however indicates that the tangential displacement discontinuity is estimated to be of the order of at most $5 \%$ of the normal one, an thus fracture is dominantly along mode 

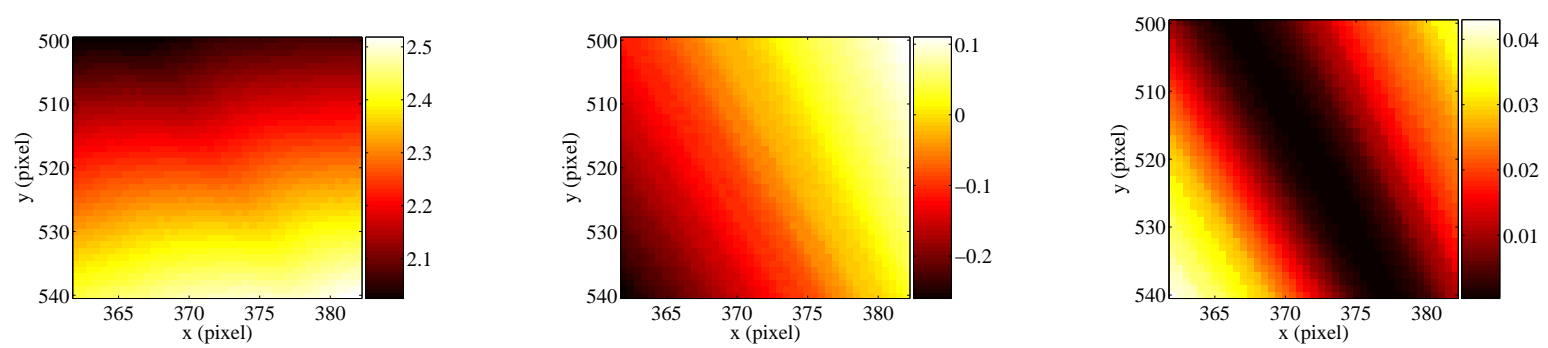

Figure 3. Maps of the stress intensity factors in mode I (a) and II (b) (in $\mathrm{MPa} \sqrt{\mathrm{m}}$ ) and of the relative global quality (c) as functions of the crack tip position. The optimum solution is located at the center of the figures.

I. At the edge of the picture where the displacement discontinuity is the largest, the opening amounts to about $500 \mathrm{~nm}$. The tangential displacement discontinuity is estimated to be about $30 \mathrm{~nm}$ or less.

\section{Summary}

A novel exploitation of Digital Image Correlation integrated with an elastic identification step based on a suited basis of functions was introduced. This technique was shown experimentally to be extremely accurate in terms of measurement of crack opening displacements accessing scales that are well below the light wavelength. This opens the way to crack identification, and even quantitative toughness measurements in situations that could not have been analyzed otherwise. For brittle materials, this technique thus appears as extremely appealing. More generally, the incorporation of mechanically significant displacement fields directly in DIC procedures, enhances both the accuracy of the displacement estimates and the reliability of the identification of mechanical properties. This same strategy can be applied to a large variety of mechanical loadings in particular for homogeneous elastic solids, but can also be extended to more complex situations (e.g., non-linear constitutive laws, or inhomogeneous media).

\section{References}

[1] B.R. Lawn, Fracture of Brittle Solids, Cambridge University Press, Cambridge (UK), 1993.

[2] M.A. Sutton, S.R. McNeill, J.D. Helm, Y.J. Chao, Advances in Two-Dimensional and Three-Dimensional Computer Vision, in: Photomechanics, Springer, (2000). 323-372.

[3] S.R. McNeill, W.H. Peters, M.A. Sutton, Estimation of stress intensity factor by digital image correlation, Eng. Fract. Mech. 28 (1987).

[4] J. Réthoré, A. Gravouil, F. Morestin, A. Combescure, Estimation of mixed-mode stress intensity factors using digital image correlation and an interaction integral, Int. J. Fract. 132 (2005) 65-79.

[5] P. Forquin, L. Rota, Y. Charles, F. Hild, A Method to Determine the Toughness Scatter of Brittle Materials, Int. J. Fract. 125 (2004) 171-187.

[6] F. Hild, S. Roux, Digital image correlation: From measurement to identification, submitted for publication (2005).

[7] T. Nose, T. Fujii, Evaluation of Fracture Toughness for Ceramic Materials by a Single-Edge-Precracked-Beam Method, J. Am. Ceram. Soc. 71 (1988) 328-333. 